Proceedings

\title{
Analytical Calculation of Load Tests of Curved Ceiling Elements Made of Carbon Concrete and Nonwovens Impregnated with Concrete ${ }^{+}$
}

\author{
Tilo Senckpiel * and Ulrich Häußler-Combe \\ Institute of Concrete Structures, Technische Universität Dresden, 01062 Dresden, Germany; \\ ulrich.haeussler-combe@tu-dresden.de \\ * Correspondence: Tilo.Senckpiel@tu-dresden.de; Tel.: +49-351-463-36912 \\ + Presented at the 18th International Conference on Experimental Mechanics (ICEM18), Brussels, Belgium, \\ 1-5 July 2018.
}

Published: 15 June 2018

\begin{abstract}
Carbon reinforced concrete (in short: carbon concrete) allows thin cross sections and lightweight, high-strength structures. This is demonstrated in this article using the example of a lightweight, prefabricated ceiling girder. In addition to the new building material carbon concrete, another innovative cement-bonded composite material is used: concrete-impregnated nonwovens. The ceiling element is a very light, slim construction that is curved in the transverse direction. In addition to the material and construction, the article describes the experimental investigation and the possibility of calculation using an analytical approach.
\end{abstract}

Keywords: carbon concrete; method for deformation calculation; concrete nonwoven; concrete shell; experimental investigations

\section{Introduction}

The construction of carbon concrete opens up many new possibilities [1]. Carbon reinforcement, for example, is not susceptible to corrosion due to normal atmospheric influences. This means that no concrete cover is required, which is only necessary to protect the reinforcement against corrosion. Compared to reinforced concrete, much thinner cross sections with the known positive effects in terms of dead weight and thus in terms of resource consumption and sustainability can be achieved in many areas of application. For this purpose, the concept of a prefabricated lightweight ceiling girder made of carbon concrete is described below. In addition to the general saving of resources, the extensive reduction in dead weight is also intended to facilitate handling during assembly. The article is aimed at extending the numerical investigations [2] by a more easily applicable, analytical approach.

\section{Design of the Ceiling Element}

Within the scope of the research project, various construction variants and spans from $3 \mathrm{~m}$ to 4.3 $\mathrm{m}$ of the lightweight ceiling element were realized and subsequently tested experimentally [2]. The elements can be used e.g. as prefabricated components to replace old floor slabs in existing buildings. A partial goal in the project was to reduce the weight so that manual assembly or the use of only light hoists is possible. In Figure 1, the usage scheme is shown based on the realized demonstrator and the calculated construction. Only textile carbon reinforcement is used. 


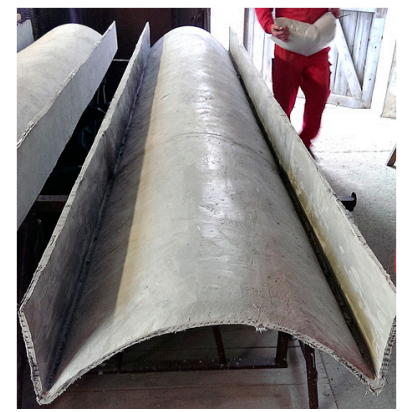

(a)

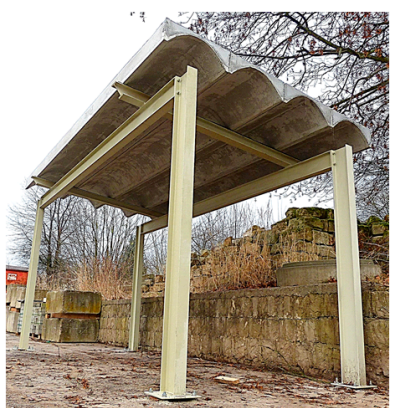

(b)

Figure 1. Ceiling element constructions: (a) a single, unfilled ceiling element (Photo: Tilo Senckpiel);

(b) shelter consisting of four filled ceiling elements as demonstrator (Photo: Ludwig Pickert).

The height of a ceiling element is limited to $20 \mathrm{~cm}$ in order to fit into existing ceiling constructions. The shell arch is formed in transverse direction along a chain line. The base thickness is $1.3 \mathrm{~cm}$, which has been increased up to $2.7 \mathrm{~cm}$ in some areas to improve overall stiffness.

\section{Materials}

The base material is a composite of two outer layers and a core layer (Figure 2a). The former is a concrete-impregnated nonwoven fabric (see Figure $2 b$ ) developed in cooperation with BCS Naturund Spezialbaustoffe GmbH and BCS Baustoff Control Service GmbH \& Co. KG, Dresden (Germany), the Sächsisches Textilforschungsinstitut e.V. STFI, Chemnitz (Germany), and our Institute of Concrete Structures. The core layer consists of fine-grained concrete reinforced with carbon fiber grids.

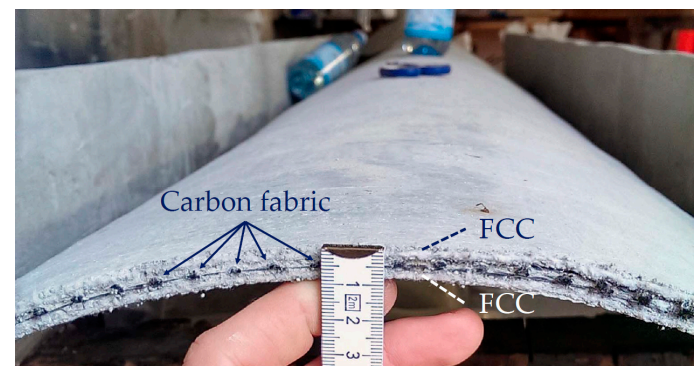

(a)

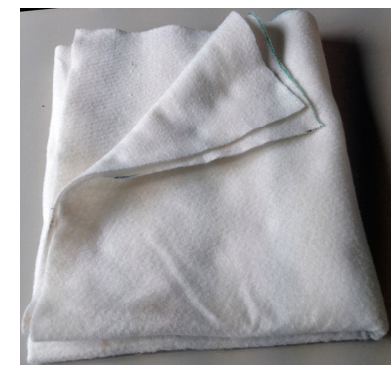

(b)

Figure 2. Materials: (a) Cross section of ceiling element; (b) unimpregnated nonwoven (Photos: Tilo Senckpiel).

\subsection{Composite Material}

The basic material for the outer layers is a needle punched nonwoven made of polypropylene fibers specially developed for the impregnation with concrete. The largest grain size of the fine concrete matrix is limited by the opening widths of the nonwoven. The thickness of a soaked layer of nonwoven FCC (Fleece Concrete Composite) is $5 \mathrm{~mm}$, enables simple production of components and serves as a carrier material in the formwork for the carbon textiles. It causes a very fine crack pattern and is extremely ductile. The symmetrical cross-sectional structure with FCC as outer layers and carbon reinforced concrete (CRC) as core is shown in Figure 3. 


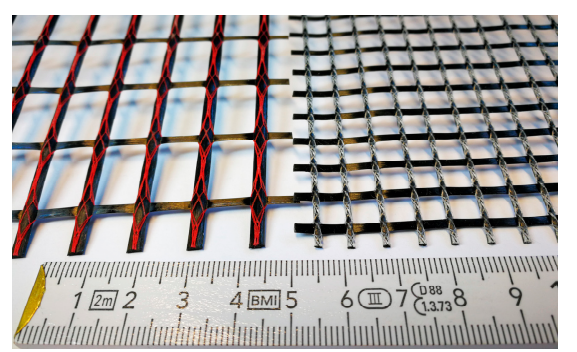

Figure 3. Carbon fabrics with a fineness of 3300/800 tex (left) and 800 tex (right) (Photo: Tilo Senckpiel).

\subsection{Carbon Reinforcement}

The reinforcement of the ceiling elements consists of two types of carbon mesh (see Figure 3). The fabric type I has a yarn fineness of 3300 tex in warp direction and a corresponding reinforcement of $1.713 \times 10^{-4} \mathrm{~m}^{2} / \mathrm{m}$. In weft direction there are 800 tex and a reinforcement of $3.080 \times 10^{-5} \mathrm{~m}^{2} / \mathrm{m}$. The mesh type II has a fineness of 800 tex in both directions and thus as reinforcement $6.160 \times 10^{-5} \mathrm{~m}^{2} / \mathrm{m}$.

\section{Experimental Tests}

\subsection{Composit Material}

During the development of the composite material, a series of tensile tests was carried out on unreinforced and reinforced tensile specimens in order to obtain the uniaxial stress-strain behavior of the material combination. The dimensions of the tensile specimens are based on the investigations by Schütze et al. [3]. The samples were $700 \mathrm{~mm}$ long, $58 \mathrm{~mm}$ wide and $5.55 \mathrm{~mm}$ high. The results of the tensile tests are shown in Figure 4. The initial Young's modulus under tensile loading can be specified with $E_{t}=12,300 \mathrm{MPa}$. If the force is not related to the entire cross section, but only to the cross section of the yarns, the modulus of elasticity is 170,000 MPa for the type I textile and 193,000 MPa for the type II textile.

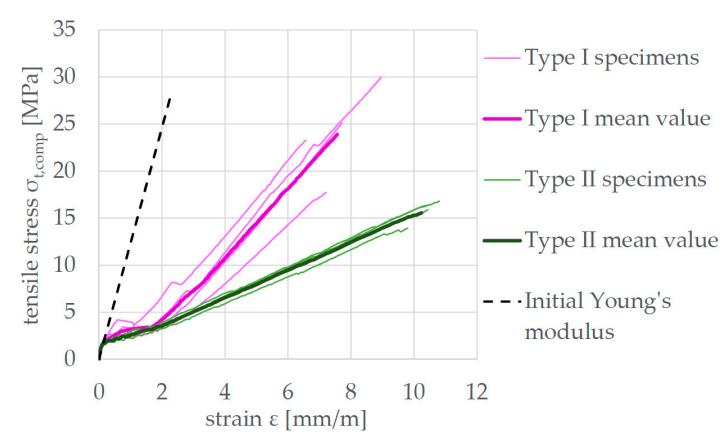

(a)

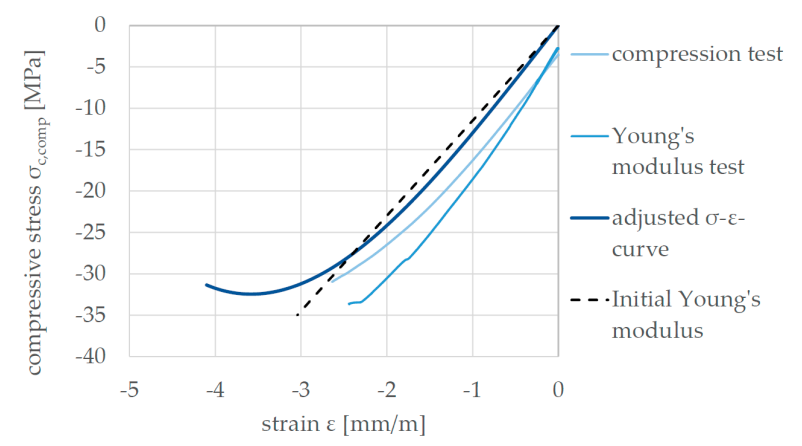

(b)

Figure 4. Stress-strain curves of the material: (a) for tensile loading; (b) for compressive loading (Graphics: Tilo Senckpiel).

The material behavior under uniaxial compressive stress was determined with the use of specimens from undamaged areas of the ceiling elements after the large-scale tests (see 4.2) were carried out. These samples contain the minimum reinforcement of type I textile present in the upper cross section. The dimensions of the specimens were: $60 \mathrm{~mm}$ long, 10 to $16 \mathrm{~mm}$ wide and $40 \mathrm{~mm}$ high and therefore do not comply with a standard. Nevertheless, tests according to [4] for determining the compressive strength and additionally according to [5] for determining the modulus of elasticity were carried out. The tests have been made with the use of strain gauges to gain the adjusted stressstrain curve, which can be taken from Figure $4 \mathrm{~b}$. The initial modulus of elasticity for compressive loading of $E_{c}=11,500 \mathrm{MPa}$ is very similar to the initial modulus of elasticity for tensile loading $E_{t}$. 


\subsection{Ceiling Element Tests}

The ceiling element construction presented here results from the experiences of previous variants. Compared to the elements from the beginning of the project, the ceiling elements have been increased in their thickness in the element center in order to minimize the high deflections of lighter constructions through the use of additional nonwoven layers. The components remain below the limit of $1 / 250$ of the span generally specified in EC2-1-1 [6], which is permitted under a quasipermanent load combination and this was achieved with a grammage of only $0.44 \mathrm{kN} / \mathrm{m}^{2}$. The length of the ceiling elements is $3.2 \mathrm{~m}$ and the span $3.0 \mathrm{~m}$. The cross-sectional dimensions are shown in Figure 5a. The experimental setup is shown in Figure 5b. The loads are transferred via a load distribution system using four $10 \mathrm{~cm}$ wide wooden templates, which results in a 6-point bending test. The distance between the templates is $1 / 4$ of the span and $1 / 8$ to the supports.

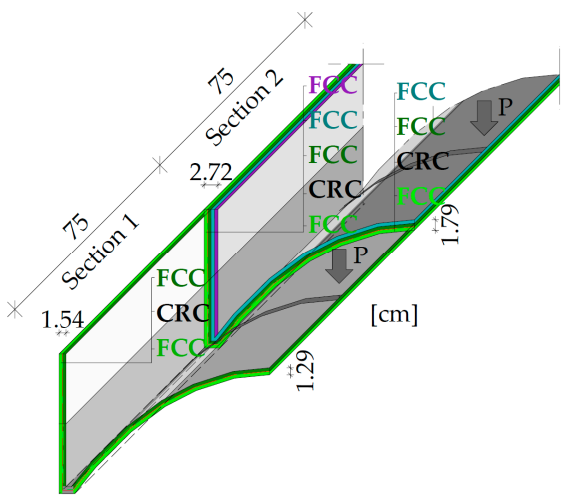

(a)

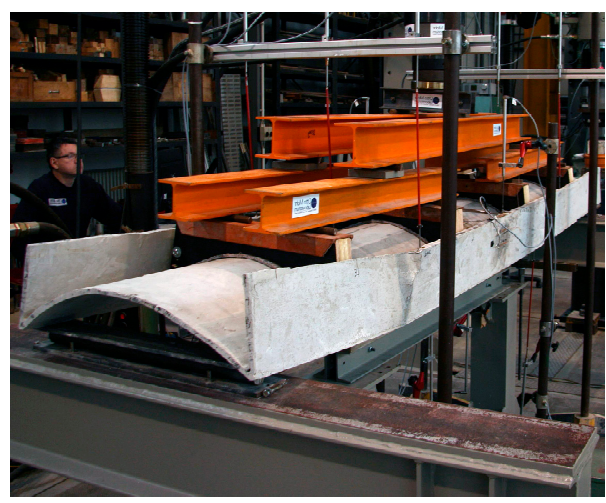

(b)

Figure 5. Ceiling element: (a) Cross section design (one quarter of the elements is shown, graphic: Tilo Senckpiel); (b) test setup and failure mode (Photo: Tilo Senckpiel).

The maximum reached load $\mathrm{P}_{\text {total }}=37 \mathrm{kN}$ is remarkably high and exceeds the design load for ordinary use of $10.5 \mathrm{kN}$. The compression failure occurs in the upper part of one of the webs (see Figure $5 b)$.

\section{Analytical Approach}

The analytical approach for calculating the force-deflection curve of the 6-point bending test is based on the principle of virtual forces. The trilinear load-bearing behavior of the experimental ceiling element test in Figure 8 (black line in Figure 8 ) is typical for reinforced concrete components and results from the change in material state (uncracked, crack formation and final crack pattern) and geometric state of the cross sections. In order to determine these states, a plane strain distribution is assumed in the cross section and the stresses and the equilibrium of internal forces are determined iteratively.

\subsection{Elastic State}

The calculation of the moments of inertia $\mathrm{I}_{1}$ and $\mathrm{I}_{2}$ assume fully activated and non-cracked cross sections of the two differently dimensioned sections shown in Figure 5. Using the CAD program AutoCAD, the moments of inertia $\mathrm{I}_{1}=4.67 \times 10^{7} \mathrm{~mm}^{4}$ (Section 1 , outer areas) and $\mathrm{I}_{2}=6.63 \times 10^{7} \mathrm{~mm}^{4}$ (middle part of the element, Section 2) can be obtained. According to [7] (p. 393), the principle of virtual forces can be used to calculate the deflection of the center of a beam. For this purpose, the bending moment curve for the 6-point bending test carried out in the experiment and the curve of the moment, which results from the virtual force applied in the middle, are determined for the singlespan beam. By integrating the diagrams of the two moments, the formula for calculating the deflection $\mathrm{w}$ as a function of the force $\mathrm{P}[\mathrm{kN}]$ can be established according to [8]:

$$
\mathrm{W}=\left(0.241 / \mathrm{EI}_{1}+1.204 / \mathrm{EI}_{2}\right) \cdot \mathrm{P} .
$$


For consistency reasons (determination of the start and end of the crack formation state), the value $E_{t}=12,300 \mathrm{MPa}$ from Figure $3 \mathrm{a}$ is used for the first, elastic range. When the material and geometry parameters are used, the following equation for calculating the deformation as a function of the force for the elastic load range results according to [8]:

$$
\mathrm{w}=1.897 \mathrm{~mm} / \mathrm{kN} \cdot \mathrm{P} \text {. }
$$

Since the method of virtual forces has been applied to the 6-point bending test with the 4 load transmission points, it should be noted that the force $\mathrm{P}$ in the equation corresponds only to a quarter of the applied machine force $P_{\text {total. }}$

\subsection{Final Crack State}

To determine the slope in the final crack state, the iterative calculation method is used to determine the maximum load and thus the final state of the strain distribution in the cross section. This results in the minimum moments of inertia of the cross sections of the element. The iterative process starts by assuming maximum strains on the outside of the cross section-on the tensilestressed side for the textile and on the compression-stressed side for the concrete. The neutral axis, the strain of the concrete and the yarns are then determined using linear interpolation. The stresses in the carbon yarns can be calculated using Hooke's law for elastic material behavior and subsequently the corresponding internal tensile forces by using the yarn cross sections. The concrete force results analogously from the integration of the cubic curve of Figure $4 \mathrm{~b}$ and the compressionstressed cross section. If the sum of the resulting forces is zero, iteration is complete. Otherwise the assumed cross sectional strains must be varied. Figure 6 shows the strain distribution over the respective cracked cross sections (Figure 7) and the corresponding stress distributions.

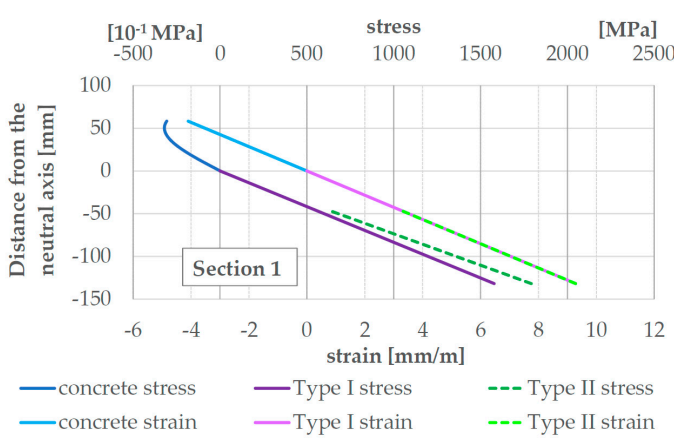

(a)

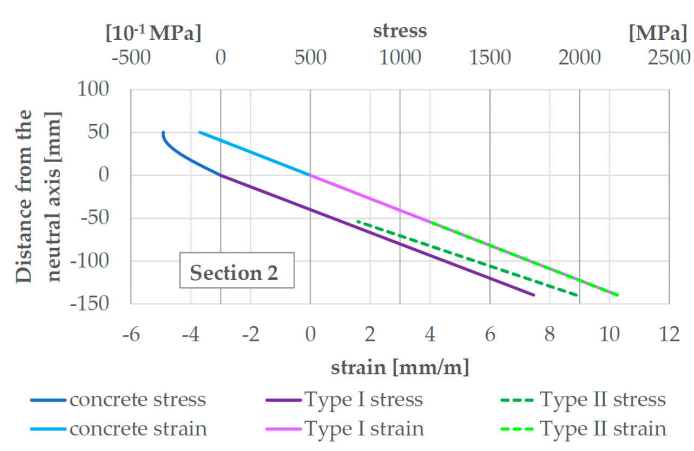

(b)

Figure 6. Strain and stress distribution with position of the neutral axis for: (a) cross Section 1; (b) cross Section 2 [8] (Graphics: Tilo Senckpiel).

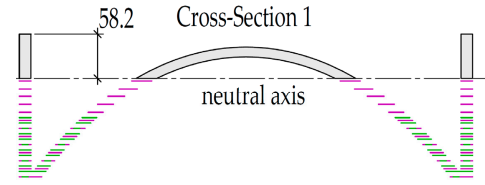

(a)

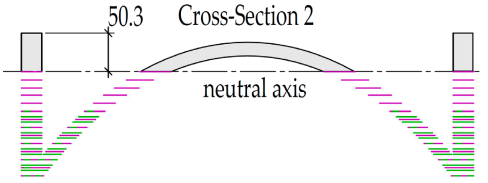

(b)

Figure 7. Cracked cross sections with position of the neutral axis for: (a) cross Section 1; (b) cross Section 2 [8] (Graphics: Ahmad Chihadeh).

After calculating the position of the neutral axes, the moments of inertia of the cracked cross sections $\mathrm{I}_{\mathrm{cr}, 1}$ and $\mathrm{I}_{\mathrm{cr}, 2}$ can be calculated. Using the ratio $\mathrm{n}$ of the modulus of elasticity of the carbon yarns used and the concrete in Section 4, the moment of inertia is obtained:

$$
\mathrm{I}_{\mathrm{cr}, \mathrm{i}}=\mathrm{I}_{\text {concrete, }, \mathrm{i}}+\Sigma\left(\mathrm{n} \cdot \mathrm{A}_{\text {tex }} \cdot \mathrm{d}^{2}\right) \text {, }
$$

where $d$ is the lever arm between the respective yarn and the neutral axis and Atex is the yarn crosssectional area. According to [8] this results in an moment of inertia of $I_{\mathrm{rr}, 1}=1.55 \times 10^{7} \mathrm{~mm}^{4}$ for the first 
cross section and $\mathrm{I}_{\mathrm{cr}, 2}=1.77 \times 10^{7} \mathrm{~mm}^{4}$ for the second. After substitution of the values in equation 1 the following is obtained:

$$
\mathrm{w}=6.791 \mathrm{~mm} / \mathrm{kN} \cdot \mathrm{P} .
$$

Figure 8 shows the course of the force deflection line (yellow). It can be seen that the slope of the calculated curve differs from the experimentally determined curve in state II.

According to Zilch et al. [7] (p. 394), a component can be divided into non-cracked and cracked areas, with the bending stiffness gradually decreasing in the transition area. To simplify matters, it is subsequently assumed that cross Section 2 is completely cracked and cross Section 1 is cracked at the point of transition to cross Section 2 and is non-cracked in the area near the support where no bending moment occurs. According to [8] this results in the mean value of $\mathrm{IMw}_{\mathrm{MW}}=3.11 \times 10^{7} \mathrm{~mm}^{4}$. If $\mathrm{I}_{1}$ is now substituted with Imw from Equation (1), the equation is obtained:

$$
\mathrm{w}=6.16 \mathrm{~mm} / \mathrm{kN} \cdot \mathrm{P} \text {. }
$$

The adjusted result (purple) is shown in Figure 8 and shows a parallel course to the state II of the experiment.

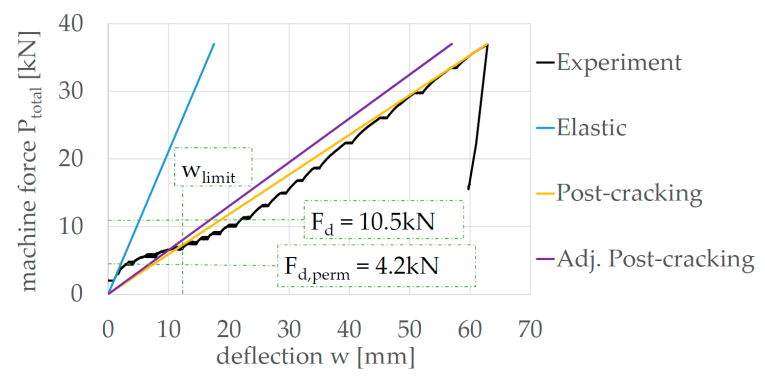

Figure 8. Force-deflection curves of the different states in comparison [8] (Graphic: Tilo Senckpiel).

\section{Conclusions}

The calculation of the load-bearing behavior of the ceiling element with the analytical approach not only shows the slope of the load-bending curve, but also shows the same type of failure in accordance with the load-bearing test carried out experimentally, whereby reaching the compressive strength of the concrete at the place of the thinnest cross section with simultaneous greatest load causes failure and not by the tensile strength of the textile.

Author Contributions: T.S. designed, performed and analyzed the experiments; Ahmad Chihadeh has implemented the analytical approach under supervision of T.S. T.S. and U.H.-C. wrote the paper.

Acknowledgments: The presented project was funded by the German Federal Ministry of Economic Affairs and Energy (BMWi) on basis of a decision by the German Bundestag.

\section{References}

1. Schladitz, F.; Tietze, M.; Lieboldt, M.; Schumann, A.; Garibaldi, M.P.; Curbach, M. Carbon reinforced concrete in construction practice. In Proceedings of the IABSE Conference-Engineering the Developing World, Kuala Lumpur, Malaysia, 25-27 April 2018.

2. Senckpiel, T.; Häußler-Combe, U. Model comparisons for a shell structure made of textile reinforced concrete. In Proceedings of the Conference on Computational Modelling of Concrete and Concrete Structures (EURO-C 2018), Bad Hofgastein, Austria, 26 February-1 March 2018; pp. 819-828.

3. Schütze, E.; Bielak, J.; Scheerer, S.; Hegger, J.; Curbach, M. Uniaxial tensile test for carbon reinforced concrete with textile reinforcement. Beton Stahlbetonbau 2018, 113, 33-47, doi:10.1002/best.201700074.

4. Testing Hardened Concrete-Part 3: Compressive Strength of test Specimens; DIN EN 12390-3:2009-07; DIN: Berlin, Germany, 2009.

5. Design of Concrete Structures - Part 1-1: General Rules and Rules for Buildings; DIN EN 12390-13:2014-06; DIN: Berlin, Germany, 2014. 
6. BS EN 1992-1-1: 2004: Eurocode 2: Design of Concrete Structures - Part 1-1: General Rules and Rules for Buildings; English Version EN 1992-1-1:2004; DIN: Berlin, Germany, 2014.

7. Zilch, K.; Zehetmaier, G. Bemessung im konstruktiven Betonbau: Grundlagen und Tragfähigkeit, 2nd ed.; Springer: Berlin/Heidelberg, Germany, 2010.

8. Chihadeh, A. Modeling and Numerical Simulation of a Carbon Concrete Lightweight Ceiling Element. Master's Thesis, Technische Universität Dresden, Dresden, Germany, 2018.

(C) 2018 by the authors. Licensee MDPI, Basel, Switzerland. This article is an open access article distributed under the terms and conditions of the Creative Commons Attribution (CC BY) license (http://creativecommons.org/licenses/by/4.0/). 